\title{
Modelling the effects of land-use and land-cover change on water availability in the Jordan River region
}

\author{
L. Menzel ${ }^{1, *}$, J. Koch ${ }^{1}$, J. Onigkeit ${ }^{1}$, and R. Schaldach ${ }^{1}$ \\ ${ }^{1}$ Center for Environmental Systems Research (CESR), University of Kassel, Germany \\ *now at: Department of Geography, University of Heidelberg, Germany
}

Received: 20 January 2009 - Revised: 24 March 2009 - Accepted: 28 April 2009 - Published: 12 August 2009

\begin{abstract}
Within the GLOWA Jordan River project, a firsttime overview of the current and possible future land and water conditions of a major part of the Eastern Mediterranean region (ca. $100000 \mathrm{~km}^{2}$ ) is given. First, we applied the hydrological model TRAIN to simulate current water availability (runoff and groundwater recharge) and irrigation water demand on a $1 \mathrm{~km} \times 1 \mathrm{~km}$ spatial resolution. The results demonstrate the scarcity of water resources in the study region, with extremely low values of water availability in the semi-arid and arid parts. Then, a set of four divergent scenarios on the future of water has been developed using a stakeholder driven approach. Relevant drivers for land-use/landcover change were fed into the LandSHIFT.R model to produce land-use and land-cover maps for the different scenarios. These maps were used as input to TRAIN in order to generate scenarios of water availability and irrigation water demand for the region. For this study, two intermediate scenarios were selected, with projected developments ranging between optimistic and pessimistic futures (with regard to social and economic conditions in the region). Given that climate conditions remain unchanged, the simulations show both increases and decreases in water availability, depending on the future pattern of natural and agricultural vegetation and the related dominance of hydrological processes.
\end{abstract}

\section{Introduction}

In the framework of the "GLOWA Jordan River" project (www.glowa-jordan-river.de), an interdisciplinary and multinational group of researchers investigates the impact of climate and land-use/land-cover change on the water resources of the Jordan River region. The area investigated in the hy-

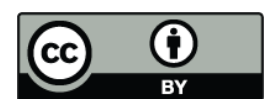

Correspondence to: L. Menzel

(lucas.menzel@geog.uni-heidelberg.de) drological sub-project includes the sub-humid, semi-arid and arid parts of the Jordan River and Dead Sea basins and their broader environs. Thus, it is stretching from the upper north of the Jordan River basin to the Gulf of Aqaba in the south, and from the Mediterranean coast to the Jordanian highlands (Fig. 1), including Israel, parts of Jordan, the Palestinian Authority, as well as parts of Lebanon, Syria and Egypt. It covers a land area of approximately $96000 \mathrm{~km}^{2}$.

The Jordan River region is ranking among the most water poor regions of the world. Over a distance of only 300$400 \mathrm{~km}$ a pronounced climate gradient occurs, with climate conditions changing from sub-humid in the north of the region (mean annual precipitation ca. $800-1000 \mathrm{~mm}$ ) (Fig. 1) to hyper-arid at the Red Sea (mean annual precipitation less than $100 \mathrm{~mm}$, potential evaporation $>2000 \mathrm{~mm}$ ). The scarce water resources are competitively shared among several nations and different water use sectors, with irrigation agriculture as one of the major water users. The $250 \mathrm{~mm}$ rainfall line (isohyet) is usually defined as the boundary between rain-fed and irrigated agriculture in the Middle East. Since no rainfall occurs during summer (Fig. 4), the cultivation of crops is typically limited to the winter season. Double cropping, i.e. the additional cultivation of summer crops, requires irrigation even in the more humid, northern parts of the region. Today, around $66 \%$ of the current water use in the region is for irrigation purposes, and about $30 \%$ is used in the domestic sector (EXACT, 1998). These numbers are however unevenly distributed over the different countries. An increasing population with a current number of 16 million, rising water demands and an expected reduction in precipitation totals make the region susceptible to frequent droughts and future water conflicts.

Our investigations aim at assessing the impact of both land-use/land-cover and climate change (Menzel et al., 2007) on the water resources of the project region. The present study focuses on land-use/land-cover scenarios which were elaborated for Israel, Jordan and the Palestinian Authority.

Published by Copernicus Publications on behalf of the European Geosciences Union. 


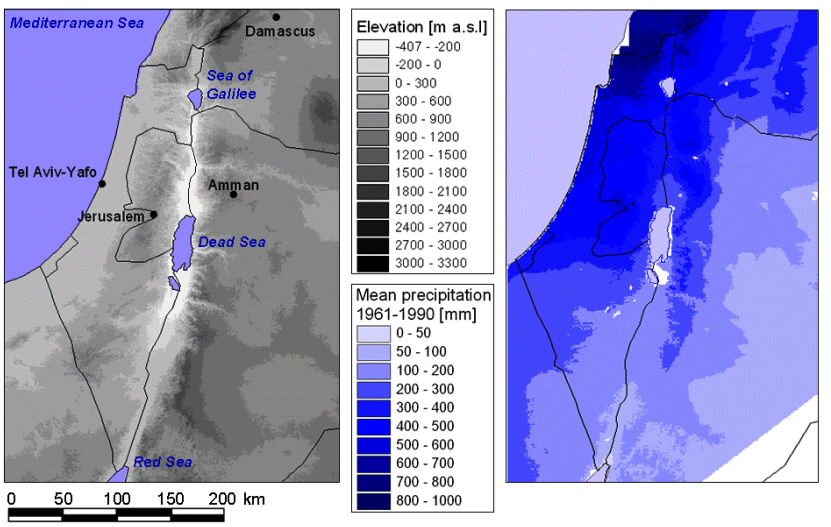

Fig. 1. Overview of the study region (left) and map of mean annual precipitation (right), generated with the interpolation procedure described in Sect. 2.4. The south-eastern corner of the region has been excluded from the investigations, due to the lack of available meteorological data.

The computation of the individual water balance components through hydrological modelling includes the water demand and water use (actual evapotranspiration) of both natural and agricultural vegetation. Therefore, we consider irrigation water requirements in our analysis, while human water demands and uses in the domestic and industrial sectors are not taken into account (which would require the application of a water use model). The investigations consider two time periods: The reference period covers the years 1961-1990, while the scenario conditions refer to the year 2050.

\section{Material and methods}

\subsection{The GLOWA Jordan River scenarios of regional de- velopment under global change}

Four scenarios on the future of water in the Jordan River region were developed together with experts from Israel, Jordan, and the Palestinian Authority by applying the so called Story and Simulation (SAS) approach (Alcamo, 2008). The aim of the iterative scenario exercise was to integrate narrative information (the storylines) provided by the regional experts and the derived quantitative estimates of scenario driving forces in a way that the scenarios can serve as a basis for the development of sustainable water management strategies for the future (for details on the scenario process see Onigkeit et al., 2009). For the scenarios, regional as well as global dynamics as for example climate change have been taken into account for a time horizon up to 2050. For this study, we consider quantitative information on population growth and related numbers of grazing livestock from two intermediate (i.e., less drastic) scenarios:

(1) The "Poverty \& Peace" scenario is characterized by a combination of peaceful development in the region without
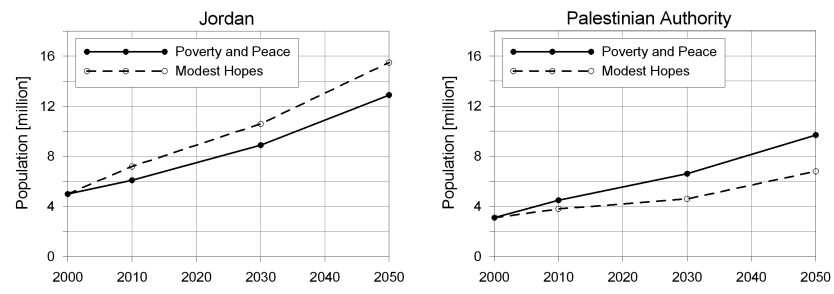

Fig. 2. Population scenarios for Jordan (left) and the Palestinian Authority (right) up to the year 2050.

economic prosperity. Despite peace and although water resources are being shared, water-stress problems, caused by climatic changes that occur over the coming decades, cannot be solved because of constrained economic growth. The overall population in the region grows by a factor of 2.3 up to the year 2050 with highest growth rates in the Palestinian Authority due to the peaceful conditions (see Fig. 2).

(2) The "Modest Hopes" scenario assumes that no peace agreement can be reached in the future but that economic prosperity prevails, kindled by international donors. This results in fairly stable conditions in the region. Education, capacity building and environmental awareness make up for some of the lack of co-operation. The overall regional population growth under this scenario is similar to that of the "Poverty \& Peace" scenario. However, for Israel and especially for Jordan population growth rates are higher under this scenario, whereas in the Palestinian Authority population growth is assumed to be much slower than under the "Poverty \& Peace" scenario.

\subsection{LandSHIFT.R model}

Based on a quantification of the scenario drivers, such as agricultural activity, number of livestock and population growth, we simulated land-use and land-cover distributions for Israel, Jordan and the Palestinian Authority up to the year 2050. This was done with LandSHIFT.R ${ }^{1}$ (Koch et al., 2008), the regional model version of the integrated model system LandSHIFT (Alcamo and Schaldach, 2006; Schaldach and Alcamo, 2006). LandSHIFT has been developed to generate spatially explicit, mid- to long-term scenarios of land-use and land-cover change. The exogenous driving forces of LandSHIFT are time series on domestic production of agricultural commodities as well as socio-economic information. The output of LandSHIFT consists, amongst others, of gridded maps displaying one dominant land-use/landcover type per grid cell.

LandSHIFT.R includes three functional components: a module for crop productivity under irrigated and rain-fed conditions, a module for productivity of (semi-)natural vegetation and a land-use change module, in the following

\footnotetext{
${ }^{1}$ Land Simulation to Harmonize and Integrate Freshwater Availability and the Terrestrial Environment - Regional Version
} 


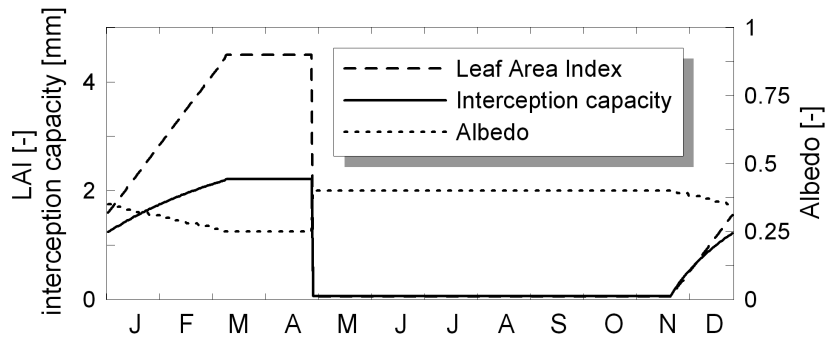

Fig. 3. Annual development of the model parameters Leaf Area Index (LAI), interception capacity and albedo in the study region, simulated by TRAIN. The example refers to the representation of winter crops/bare soil (summer period) in the model.

referred to as LUC-module. The module for crop productivity is based on a modified version of the ecosystem model DayCent (Parton et al., 1998). The main task of this module is to provide crop yield maps to the LUC-module (Stehfest et al., 2007). The module for productivity of (semi-)natural vegetation is based on the WADISCAPE model (Köchy, 2007; Köchy et al., 2008), which delivers information on current and future stocking capacity and landscape productivity to the LUC-module. In the LUC-module, the demand for area intensive activities (e.g., agricultural production, grazing) is regionalized to a grid with a spatial resolution of 30 arc s (approx. $1 \mathrm{~km} \times 1 \mathrm{~km}$ ). This module is structured into three sub-modules covering the dynamics of the most important land-use activities of the study region which are "urban", "crop cultivation" (i.e., cereals, fruits, vegetables and other crops) and "grazing". Each sub-module includes routines to assess the suitability of each grid cell for the respective landuse activity and to allocate the corresponding demands to the most suitable grid cells.

\subsection{TRAIN model}

TRAIN is a physically-based, spatially distributed hydrological model which includes information from comprehensive field studies of the water and energy balance of different surface types, including natural vegetation and agricultural land (Menzel, 1997, 2007). It has been designed to simulate the spatial pattern of the individual water budget components at different spatial and temporal scales. Typical applications are at the point and the regional scale, with temporal resolutions of one hour or one day. For an areal simulation of the water budget, the investigated spatial unit is subdivided into a regular grid, with square sizes dependent on the available input data and their spatial resolution (typically in the range of $1 \mathrm{~km} \times 1 \mathrm{~km}$ ). Special focus in TRAIN is on the vertical exchange of water at the soil-vegetationatmosphere interface, with evapotranspiration as one of the principal mechanisms. The simulation of transpiration is based on the Penman-Monteith equation (Monteith, 1965). It depends on the calculation of canopy resistances, which are

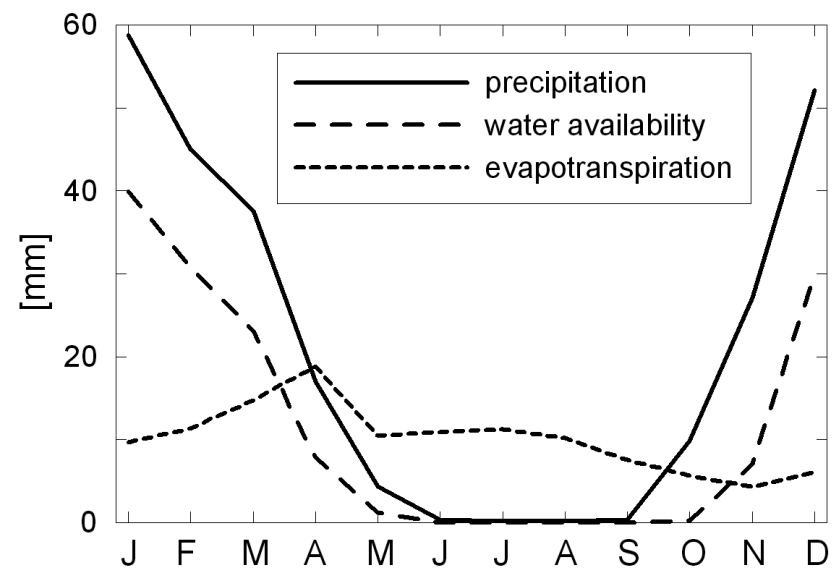

Fig. 4. Mean seasonal development of precipitation (derived from station data), water availability (runoff and groundwater recharge; simulated) and actual evapotranspiration (simulated). Data refer to the period 1961-1990 (land-use/land-cover base year 2000) and represent areal means over the entire study region. Simulations were carried out with TRAIN and are based on daily simulation intervals. Further explanations in the text.

modified by the state of growth of the vegetation, soil moisture status and weather conditions (Menzel, 1996). Interception and interception evaporation are simulated according to Menzel, 1997. The maximum amount of water that can be stored in the canopy (the interception capacity) is dependent on the seasonal development of the Leaf Area Index (LAI) of the respective vegetation type (Fig. 3). Interception evaporation is modelled to occur with different intensities, as a function of the actual amount of water accumulated in the canopy and the present weather conditions. The calculation of the soil water status and of percolation follows the conceptual approach from the HBV-model (Bergström, 1995). The simulated amounts of deep percolation and of infiltration excess (which leads to runoff) are aggregated for each pixel and termed as water availability, i.e., the amount of water theoretically disposable for certain uses.

The application of TRAIN to agricultural land implies the consideration of the same crop types as included in the LandSHIFT.R model (see Sect. 2.2). Their proper parameterisation, such as LAI or albedo (Fig. 3), the respective growing stage and possible irrigation water requirements are simulated by the model for each time step. As soon as the simulated soil water content drops below a critical limit (usually in the range of $30 \%$ of the plant available water capacity), the model assumes irrigation until a sufficient soil water status (usually field capacity) is reached. The amount of water needed to compensate soil water stress is supposed to equal irrigation water requirement. Note that this approach assumes that irrigation water requirements can always be met, which would lead to optimal crop growth. However, actual irrigation water use may be lower than the simulated requirement, since water supply for irrigation might be limited. 


\subsection{Study setup}

In this study, the hydrological model TRAIN was run on a $1 \mathrm{~km} \times 1 \mathrm{~km}$ grid with daily time steps. Due to limited data availability, a $1 \mathrm{~km}$ spatial resolution is currently the highest possible degree of detail for the study region. For an areal analysis of the water balance, a number of spatial data was required as input to TRAIN. Meteorological data (precipitation, air temperature, relative humidity, wind speed and solar radiation) were taken from daily observations over the period 1961-1990 (after 1990, data availability has been poor). The spatially uneven distribution of the stations and the varying meteorological conditions over short distances required the application of a sophisticated interpolation method. For each day of the 30-year period, a multiple regression analysis was performed to select significant predictor variables for the interpolation. Elevation, distance to the coast, but also the $\mathrm{x}$ and $y$-coordinates of the stations were considered as possible regressors. The interpolation procedure, described in more detail in Wimmer et al. (2009), consists of a number of interpolation methods which are selected with respect to the regression model and the climate variable. In order to assess the validity of the model, cross validations were performed for each day and climate variable. All interpolations were carried out using the R package gstat (Pebesma, 2004), with a final resolution of $1 \mathrm{~km}$. An exemplary result of the interpolation procedure is given in Fig. 1: mean annual precipitation was aggregated from daily interpolation fields. The map shows a close relationship with elevation; however, this is not always the case when considering daily interpolated precipitation fields.

Information regarding topography was taken from the global Digital Elevation Model (DEM) GTOPO30 (USGS, 2009a) with a horizontal grid spacing of 30 arc s (approximately $1 \mathrm{~km} \times 1 \mathrm{~km})$. No consistent soil and land-use/landcover data base was available for the study region. Therefore, information from different data sources had to be integrated and joined to individual maps covering the whole region. A detailed, digital soil map of Israel was elaborated at the University of Bochum, Germany (Marschner, personal communication, 2008) which is based on Singer (2007) and the soil associations map of Israel. For the rest of the study region, the global map of soil properties ISRIC-WISE (Batjes, 2006) was available. For both data sources, soil depth, profile available water capacity and basic hydraulic properties were derived using as far as possible the same methodology. The LandSHIFT.R results were geographically mapped to the $1 \mathrm{~km} \times 1 \mathrm{~km}$ grid required by the TRAIN model. For the grid cells where no LandSHIFT.R simulation results are available (Lebanon, Syria, Egypt), information was derived from the IGBP Global Land Cover Characterization GLCC (Loveland et al., 2000; USGS, 2009b) which is available on a $1 \mathrm{~km}$ grid size. The DEM as well as the individual soil and land-use/land-cover layers were re-projected to congru- ent grids and aggregated to a common spatial resolution of $1 \mathrm{~km} \times 1 \mathrm{~km}$.

In this study, three land-use/land-cover maps were prepared to serve as input for the hydrological model TRAIN: one for the year 2000 and two for the year 2050 under the scenarios "Poverty \& Peace" and "Modest Hopes", respectively. Note that no land-use/land-cover scenarios were generated for the regions outside the actual scenario exercise, i.e., Lebanon, Syria and Egypt. However, parts of these countries are included in the TRAIN analysis (Fig. 1). Therefore, land-use/land-cover remains unchanged for these regions on the scenario maps. The individual TRAIN runs were driven with the same climate data set which refers to the period 1961-1990, i.e., no combination of land-use/land-cover scenarios and climate change scenarios was applied (which is outside the scope of this study).

Applications of TRAIN for the land-use classes representing cropland were carried out assuming one growing season, with the cultivation of winter crops. This might lead to an underestimation of irrigation water requirements for those agricultural areas on which summer crops are grown. However, no information about criteria for the cultivation of summer crops were available. Also, no spatially explicit data set on the agricultural areas equipped for irrigation exists on the required spatial resolution. Therefore, irrigation was assumed to be possible on any of the pixels allocated as agricultural land, unless the criteria described in Sect. 2.3 are fulfilled. So far, the growing seasons of the individual crops as well as of natural vegetation were held static, i.e., no year-to-year variations due to differing meteorological conditions were taken into account. TRAIN was iteratively run on those grid cells which are expected to contain a high degree of sub-grid variability, such as heterogeneous soil and land-use/land-cover combinations. For example, the land-use class "urban" was divided into two sub-classes representing sealed surfaces and park areas.

\section{Results}

\subsection{Water resources distribution under current condi- tions}

Figure 4 shows the mean seasonal development of precipitation (based on interpolated, daily observations), water availability and actual evapotranspiration (simulated by TRAIN; daily model data were aggregated to long-term averages) over the entire study region. Note that this is an aggregated view over the (large) area investigated, including both subhumid, semi-arid and arid conditions, with the latter dominating in their areal extent. Remember also that our definition of water availability includes the amount of water theoretically accessible to humans (i.e., runoff and groundwater recharge) but excludes water stored in the soil; yet, the latter is considered in the simulation of actual evapotranspiration. 

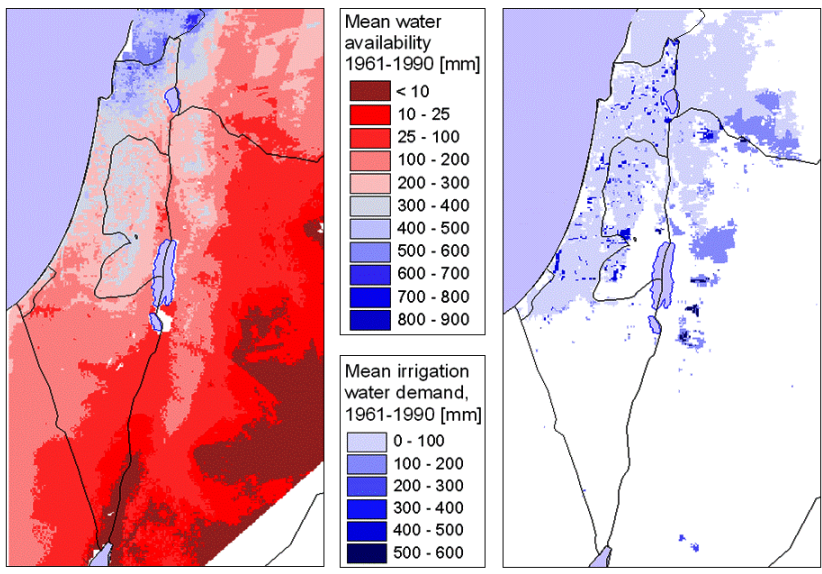

Fig. 5. Simulated, mean water availability (runoff and groundwater recharge; left) and simulated irrigation water requirement (right) for current conditions (climate base period 1961-1990, land-use/landcover base year 2000). Note that irrigation water requirement was only computed for agricultural land.

According to the simulations, water availability shows - like precipitation - a marked seasonal behaviour, with highest values at the beginning of a year, and a subsequent, continuous decrease towards summer. It is only in autumn that water availability rises again. The respective curve in Fig. 4 shows a retarded onset with regard to the precipitation increase. This is caused by the dry soils which first need to be wetted in order to generate excess water. Simulated actual evapotranspiration shows a different behaviour. It rises from the beginning of the year until it peaks during late spring, when soil moisture remains at relatively high levels and plant development is at its maximum (see for example the LAI development represented for winter crops in Fig. 3). Later in the year then, actual evapotranspiration first remains on a plateau before it slowly decreases during late summer and autumn, when water availability in the soils is low and plants are not well developed.

The map of simulated mean water availability (Fig. 5; based on daily simulation steps) gives a spatially detailed view on the water resources of the region. It is obvious that the sharp precipitation gradient is reflected in the distribution of the water availability. However, there is an increasing gap between mean precipitation and mean water availability from the northern to the southern and eastern parts of the region, i.e., from the sub-humid to the arid and hyper-arid climate zones, where low and extremely low values $(<10 \mathrm{~mm} / \mathrm{a})$ of water availability occur. It is clear that in the respective desert zones, there is - on an average - nearly no water available for groundwater recharge or surface runoff. According to the simulations with TRAIN, actual evapotranspiration in this regions amounts to $85-90 \%$ of precipitation, or even more. The central and northern parts of the study region which are not too far away from the coastline show

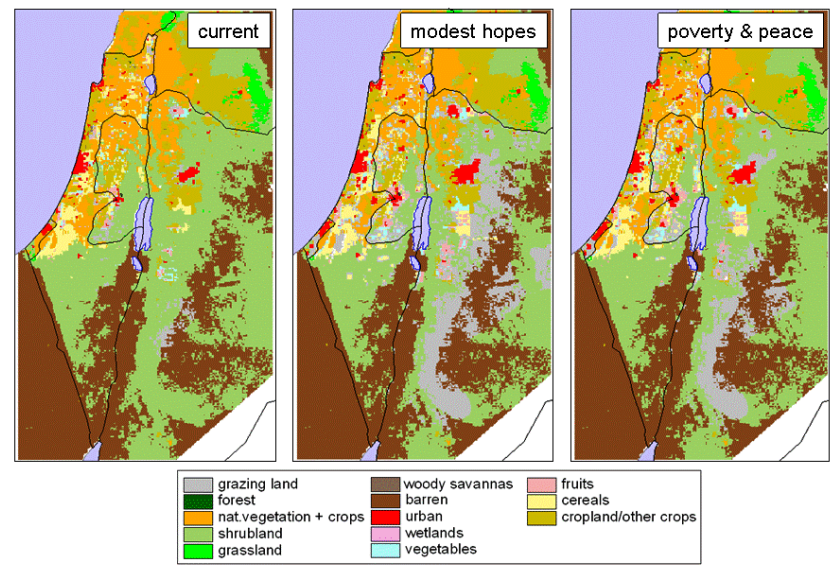

Fig. 6. Current (year 2000) and future (year 2050) land-use/landcover distribution in the region, simulated with LandSHIFT.R. Future conditions are given for the scenarios "Modest Hopes" and "Poverty \& Peace". Note that the simulation of land-use/land-cover change is restricted to Israel, Jordan and the Palestinian Authority.

clearly higher amounts of water availability, in the range of $200-500 \mathrm{~mm} / \mathrm{a}$. The highest values occur along the IsraeliLebanese border and peak in the Mount Hermon region and in the Anti-Lebanon. Beside precipitation, the distribution of soils with their varying soil water capacities as well as the land-use and land-cover conditions play a role in the distribution of the water resources. This is indicated by a large number of small-scale patterns in the distribution of water availability which do not clearly follow the precipitation distribution.

The right graph in Fig. 5 shows the simulated, mean irrigation water requirements of the region. Note that by definition the spatial extent of the irrigated areas follows the areal distribution of agricultural land (Fig. 6). It is obvious that the prevailing values lie in the range of $0-100 \mathrm{~mm} / \mathrm{a}$ and that extraordinary high values are absent. This might be ascribed to one of the boundary conditions of the application of TRAIN, namely that only one growing season occurs, during the relatively wet winter. The highest irrigation water requirements (between 500 and $600 \mathrm{~mm} / \mathrm{a}$ ) are unevenly distributed over a larger part of the region - this emphasises that there is a number of factors which determines irrigation water requirements. Apart from atmospheric conditions, differing soil water capacities and variable land-use (i.e., different crop types) have a clear impact on the simulated irrigation amounts.

\subsection{Impact of land-use and land-cover change on the water resources}

Current land-use/land-cover conditions as well as the two scenarios applied in this study are shown in Fig. 6. The percentages of the individual land-use/land-cover classes at the total area as well as their changes under the two scenarios are listed in Table 1 . The mapping of land-use/land-cover 
Table 1. Overview of the current (reference year 2000) and future (year 2050) land-use/land-cover in the region, expressed by the number of grid cells allocated by the particular classes. Numbers in brackets for current conditions are the respective percentages of the individual classes at the total area. Numbers in brackets for future conditions are percentage changes of the classes by comparison with the current state. Minor percentages are discarded.

\begin{tabular}{lccc}
\hline land-use/land-cover class & current & modest hopes & poverty \& peace \\
\hline shrubland & $39641(41.1 \%)$ & $27981(-29.4 \%)$ & $32547(-17.9 \%)$ \\
barren/sparsely vegetated & $30542(31.7 \%)$ & 30541 & 30541 \\
nat. vegetation/cropland mosaic & $9877(10.3 \%)$ & $8400(-15.0 \%)$ & $8765(-11.3 \%)$ \\
cropland (undifferentiated) & $8748(9.1 \%)$ & 8751 & 8748 \\
cereals & $2513(2.6 \%)$ & $2702(+7.5 \%)$ & $2544(+1.2 \%)$ \\
grazing land & $1243(1.3 \%)$ & $12927(+940 \%)$ & $8204(+560 \%)$ \\
grassland & $1177(1.2 \%)$ & $1162(-1.3 \%)$ & $1165(-1.0 \%)$ \\
urban & $974(1.0 \%)$ & $1546(+58.7 \%)$ & $1406(+44.4 \%)$ \\
fruits & $814(0.9 \%)$ & $1199(+47.3 \%)$ & $1226(+50.6 \%)$ \\
vegetables & $732(0.8 \%)$ & $951(+29.9 \%)$ & $992(+35.5 \%)$ \\
woody savannas & 36 & 32 & 35 \\
forest & 19 & 12 & 12 \\
wetlands & 2 & 2 & 2 \\
Total & $96318(100 \%)$ & 96318 & 96318 \\
\hline
\end{tabular}

shows that the majority of the region (more than 70\%) is currently covered by natural vegetation, mainly shrubland and barren (the sparsely covered and non-vegetated areas in the deserts). According to the scenarios, natural vegetation is projected to strongly decrease, while the demand for grazing shows an enormous rise in both scenarios, as a result of population growth and a related increase in livestock numbers. Since the storyline for the scenario "Modest Hopes" indicates a high awareness of environmental issues, the simulations for this scenario were carried out under the assumption of sustainable grazing management. This generally leads to a larger spatial extent of grazing area (Koch et al., 2008) (Fig. 6). Note that the highest increase of grazing land occurs in Jordan. This is a consequence of the predicted, strong population growth in this country (Fig. 2) and a low degree of competing demands between different land-use activities.

Further effects of the projected population development can be seen in an increase of urban sprawl in the vicinity of already existing urban centres (Fig. 6), however, with clear differences between the two scenarios (remember that the "Poverty \& Peace" scenario shows a relatively low population growth rate - see Fig. 2). Currently, about $10 \%$ of the region is used as cropland, while fruits and vegetables are grown on comparatively small areas. These areal shares are projected to change, with a small rise of the land area cultivated with cereals and clear increases in areas dedicated for the cultivation of fruits and vegetables (with minor differences between the two scenarios).

The possible hydrological effects of the two land-use/landcover scenarios are shown in Fig. 7. Projected changes in water availability show a spotty pattern over the study region, with both increases and decreases in water availabil-
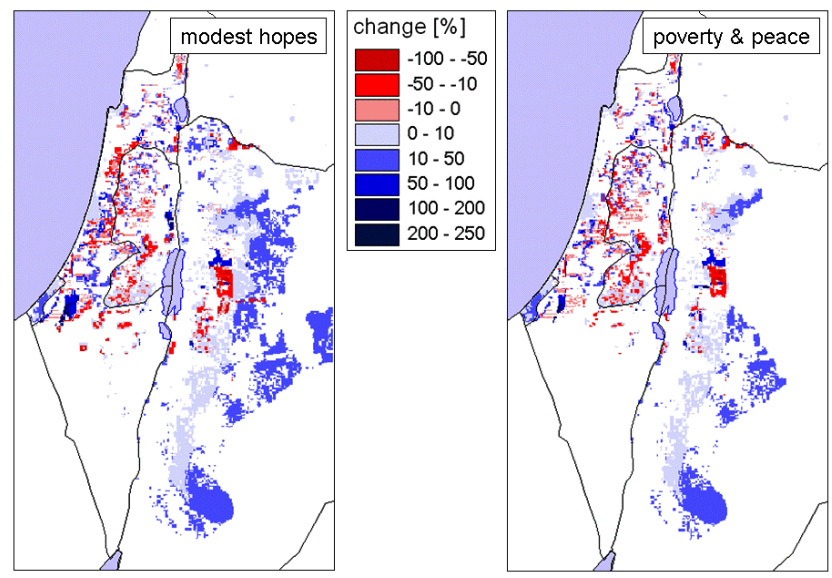

Fig. 7. Simulated, mean changes in water availability (runoff and groundwater recharge) for the two land-use/land-cover change scenarios "Modest Hopes" (left) and "Poverty \& Peace" (right). Note that changes from small absolute numbers might result in high percentages.

ity. For both scenarios, a notable increase in water availability occurs in major parts of Jordan. This is correlated with the projected increase in grazing land. In TRAIN, the category grazing land is similarly treated as shrubland, but with a lower LAI. This results in lower transpiration rates which lead to higher amounts of water availability simulated by the model. An average increase in simulated water availability also occurs on areas which are assumed to be affected by urban expansion. In this case, the increasing share of sealed surfaces leads to higher volumes of simulated surface runoff. Projected decreases in water availability appear in 
those areas where natural vegetation was converted into agricultural land, which leads to higher water demands for transpiration and biomass production. This also affects irrigation water requirements. With respect to current conditions, the "Modest Hopes" scenario results in an increase of $11 \%$ in water required for irrigation. For the "Poverty \& Peace" scenario however, no change in average irrigation water requirements arises. This might be related to the smaller increase of land cultivated with cereals in the "Poverty \& Peace" scenario (Table 1), as a consequence of the relatively low population growth rates and lower per capita food demands in this scenario.

\section{Discussion and conclusions}

This study gives for the first time a coherent overview of the land-use/land-cover and water conditions of a major part of the Eastern Mediterranean region, with the highest possible spatial detail. Our model results for the current state (period 1961-1990) demonstrate the scarcity of water resources in major parts of the study region, with extremely low values of water availability in the semi-arid and arid parts of the region. Our investigations show that actual evapotranspiration (in clear contrast to potential evapotranspiration) is low in the region - its upper limit is controlled by precipitation - but it reaches high values under irrigated conditions. Irrigation has been confirmed to be a prerequisite for most agricultural activities in the region, but its required amount is very much dependent on the cropping pattern. In comparison with the few available, large-scale water balance analyses of the study region (e.g., Baumgartner and Reichel, 1975) we think that our data for current conditions are reliable and might be applied to further analyses. However, we consider our investigations as preliminary since major processes in both applied models need to be refined and adapted to the specific conditions of the region. For example, the land-use/land-cover types considered in Land.SHIFT.R need better parameterisation in TRAIN, with a seasonal behaviour dependent on actual atmospheric conditions. Furthermore, the effects of grazing require better reproduction in TRAIN, for example with a description and quantification of the susceptibility of grazing land against erosion. Since data availability was not sufficient to continue our analysis for the period after 1990, possible recent trends, such as rising temperatures or an increase in rainfall variability, could not be considered in this study.

Another result of this work is that our land-water investigations could be achieved through a one-way coupling of two very different models, LandSHIFT.R and TRAIN. So far, a harmonization of data requirements of the two models and data exchange between them was successfully implemented. Coming work will include a feedback between the two models, so that the generation of land-use/land-cover scenarios will be carried out in an iterative process through continuous information exchange between LandSHIFT.R and TRAIN. Finally, it is envisaged to include climate change scenarios in our analysis, so that projected, climate related reductions in water availability can be used as a criterion to modify the land-use/land-cover scenarios in such a way that they take into account options to mitigate the adverse impacts of climate change. This last option requires however close cooperation with the stakeholder driven SAS approach in order to match the different interests and motivations between policy makers and scientists.

Apart from the shortcomings described above, we have shown that the impact of land-use and land-cover changes on water resources is obvious. Given similar mean precipitation, water availability is simulated to increase in those parts of the region where urban areas and/or grazing land are projected to increase, due to higher surface runoff and reduced actual evapotranspiration. However, this result does not allow a statement about the usability of higher surface runoff and groundwater recharge rates although its knowledge would be important regarding the expected increase in human water demands. Therefore, it is planned to include the representation of water harvesting techniques, such as managed aquifer recharge, as well as an assessment of current and future human water demands in our investigations within the GLOWA Jordan River project.

Acknowledgements. This study has been funded by the German Ministry for Education and Research (BMBF), Contract Number $01 \mathrm{LW}$ 0502. We are grateful to Stefan Schlaffer who supplied us with the interpolated meteorological data. Two anonymous reviewers gave helpful comments for the improvement of this article.

Edited by: B. Schmalz, K. Bieger, and N. Fohrer

Reviewed by: two anonymous referees

\section{References}

Alcamo, J.: The SAS approach: combining qualitative and quantitative knowledge in environmental scenarios, in: Environmental futures: The practice of environmental scenario analysis, Developments in integrated environmental assessment, edited by: Alcamo, J., 2, Elsevier, Amsterdam, The Netherlands, 123-150, 2008.

Alcamo, J. and Schaldach, R.: LandShift: global modelling to assess land use change. EnviroInfo 2006: Managing Environmental Knowledge, Proc. 20th Int. Conf. on Informatics for Environmental Protection, Shaker Verlag, Aachen, Germany, 223-230, 2006.

Batjes, N. H.: ISRIC-WISE derived soil properties on a 5 by 5 arc minutes global grid. Report 2006/02, available at: http: //www.isric.org, ISRIC-World Soil Information (with data set), Wageningen, The Netherlands, 2006.

Baumgartner, A. and Reichel, E.: The World Water Balance. R. Oldenbourg Verlag, München, Wien, 179 pp., 1975. 
Bergström, S.: The HBV model, Computer Models of Watershed Hydrology, edited by: Singh, V. P., Water Resources Publications, Highlands Ranch, 443-476, 1995.

Executive Action Team (EXACT): Middle East Water Data Banks Project. Overview of Middle East water resources, available at: http://exact-me.org/overview/index.htm, last access: 19 January 2009, 1998.

Koch, J., Schaldach, R., and Köchy, M.: Modeling the impacts of grazing land management on land-use change for the Jordan River region, Global Planet. Change, 64, 177-187, 2008.

Köchy, M.: Grazing capacity of Middle East landscapes under contrasting climate change scenarios. 37. Jahrestagung der Gesellschaft für Ökologie, Verh. Ges. f. Ökol., 37, 137 pp., 2007.

Köchy, M., Mathaj, M., Jeltsch, F., and Malkinson, D.: Resilience of stocking capacity to changing climate in arid to Mediterranean landscapes, Reg. Environ. Change, 8, 73-78, 2008.

Loveland, T. R., Reed, B. C., Brown, J. F., Ohlen, D. O., Zhu, Z., Yang, L., and Merchant, J. W.: Development of a global land cover characteristics database and IGBP DISCover from $1 \mathrm{~km}$ AVHRR data, Int. J. Remote Sens., 21, 1303-1330, 2000.

Menzel, L.: Modelling canopy resistances and transpiration of grassland, Phys. Chem. Earth, 21(3), 123-129, 1996.

Menzel, L.: Modellierung der Evapotranspiration im System Boden-Pflanze-Atmosphäre, Zürcher Geographische Schriften, 67, Geographisches Institut, ETH, Zurich, Switzerland, 128 pp., 1997.

Menzel, L.: Model based simulation of the water balance of forests on different spatial scales, in: The role of forests and forest management in the water cycleProgress in Hydro Sciences and Engineering, edited by: Feger, K.-H., Yanhui, W., Bernhofer, Ch., and Seegert, J., 3/2007, Dresden Water Center, Dresden, Germany, 309-319, 2007.

Menzel, L., Teichert, E., and Weiß, M.: Climate change impact on the water resources of the semi-arid Jordan region, edited by: Heinonen, M., Proc. 3rd Int. Conf. on Climate and Water, Helsinki, Finland, 320-325, 2007.
Monteith, J. L.: Evaporation and environment, Symp. Soc. Exp. Biol., 19, 205-234, 1965.

Parton, W. J., Hartman, M., Ojima, D., and Schimel, D.: DAYCENT and its land surface submodel: description and testing, Global Planet. Change, 19, 35-48, 1998.

Onigkeit, J., Alcamo, J., and Luebkert, B.: The procedure for developing the GLOWA Jordan River scenarios, Internal report, Center for Environmental Systems Research, University of Kassel, Germany, 2009.

Pebesma, E. J.: Multivariable geostatistics in S: the gstat package, Comp. Geosci., 30, 683-691, 2004.

Schaldach, R. and Alcamo, J.: Coupled simulation of regional land use change and soil carbon sequestration: a case study for the state of Hesse in Germany, Environ. Model. Softw., 21, 1430 1446, 2006.

Singer, A.: The soils of Israel, Springer-Verlag, Berlin, Heidelberg, 306 pp., 2007.

Stehfest, E., Heistermann, M., Priess, J. A., Ojima, D. S., and Alcamo, J.: Simulation of global crop production with the ecosystem model DayCent, Ecol. Model., 209, 203-219, 2007.

USGS: U.S. Geological Survey, EROS Data Center: GTOPO30 Digital Elevation Model, available at: http://edc.usgs.gov/ products/elevation/gtopo30/gtopo30.html, last access: 19 January 2009, 2009a.

USGS: U.S. Geological Survey, EROS Data Center: Global Land Cover Characterization, available at: http://edcsns17.cr.usgs. gov/glcc/, last access: 19 January 2009, 2009 b.

Wimmer, F., Schlaffer, S., Aus der Beek, T., and Menzel, L.: Distributed modelling of climate change impacts on snow sublimation in Northern Mongolia, Adv. Geosci., this special volume , 2009. 